\title{
About the Artist: Lingikoni Vaka'uta
}

\begin{abstract}
As an economics student at the University of the South Pacific (USP), Lingikoni Vaka'uta never imagined he would become an artist. Nearly finished with his degree yet unsatisfied, he joined the first painting workshop at the Oceania Centre for Arts and Culture in 1998. He was given a piece of canvas and told to tell his story. Unexpectedly, he found inspiration in his memories of growing up in Lapaha, Tonga, and an answer to what had been missing. What emerged were the beginnings of a style inspired by Tongan practices, legends, and heritage.
\end{abstract}

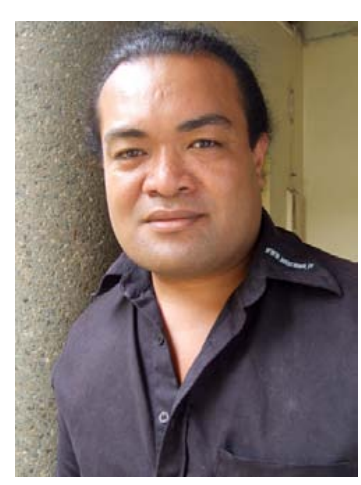

Рното ву

Katherine Higgins

Lingikoni continues to find inspiration in the poetic and insightful Tongan metaphors and stories he has learned or composed. The multifaceted meanings and reinterpretation in Lingikoni's works are rooted in his memories of Tonga, yet visually they are distinctively contemporary. His stylized representations of gods, animals, and tattooed bodies do not imitate the work of his ancestors; however, the themes rejuvenate cultural connections, because by relating to his home and past, he connects with his ancestors and fonua (land). Depicting a legendary scene such as Maui slowing the sun (page I44), or a provocative metaphor as in Meeting of the Fishes (page 72), Lingikoni challenges, intrigues, and plays with imagery composed of smaller motifs, presenting stories within stories as if tattooing his/stories across the artwork.

Whether sharing his own experiences, offering technical advice through participative exchange, or facilitating the affairs of the Red Wave Collective, Lingikoni's participation is fundamental to the operations of the Oceania Centre. He is a confidante and mentor to his fellow artists, as Epeli Hau'ofa is to him, making it natural for Lingikoni to become the collective's coordinator.

Aside from painting, drawing, sculpting, coordinating, and exhibiting with the Red Wave Collective, Lingikoni is completing a Master of Arts in Pacific Studies at the university. 


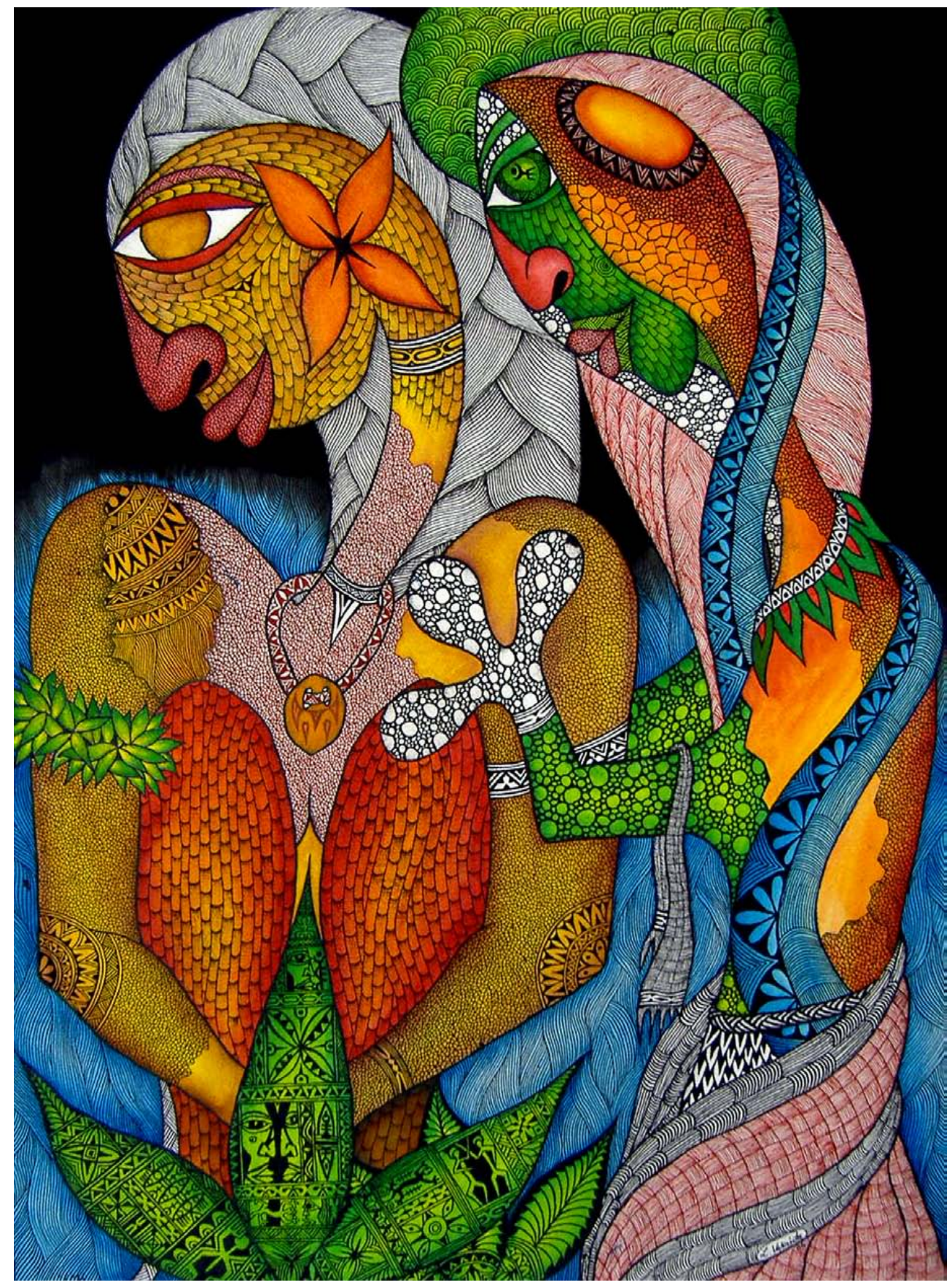

The Charmer

Ink on paper, $2006,77 \mathrm{~cm} \times 57 \mathrm{~cm}$.

Photo by Katherine Higgins. 


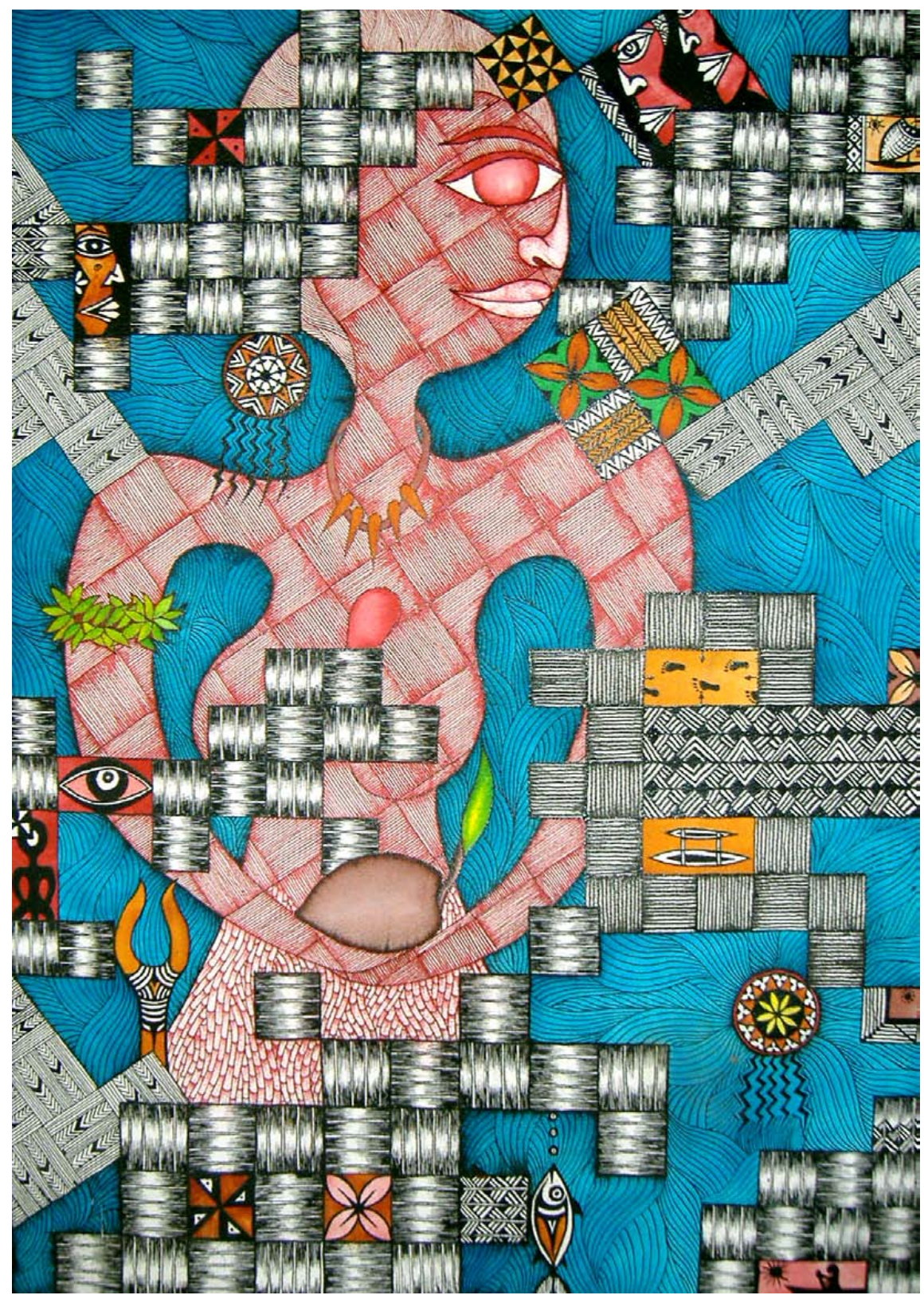

Vaka Vuku

Ink on paper, $2006,77 \mathrm{~cm} \times 57 \mathrm{~cm}$.

Photo by Katherine Higgins. 


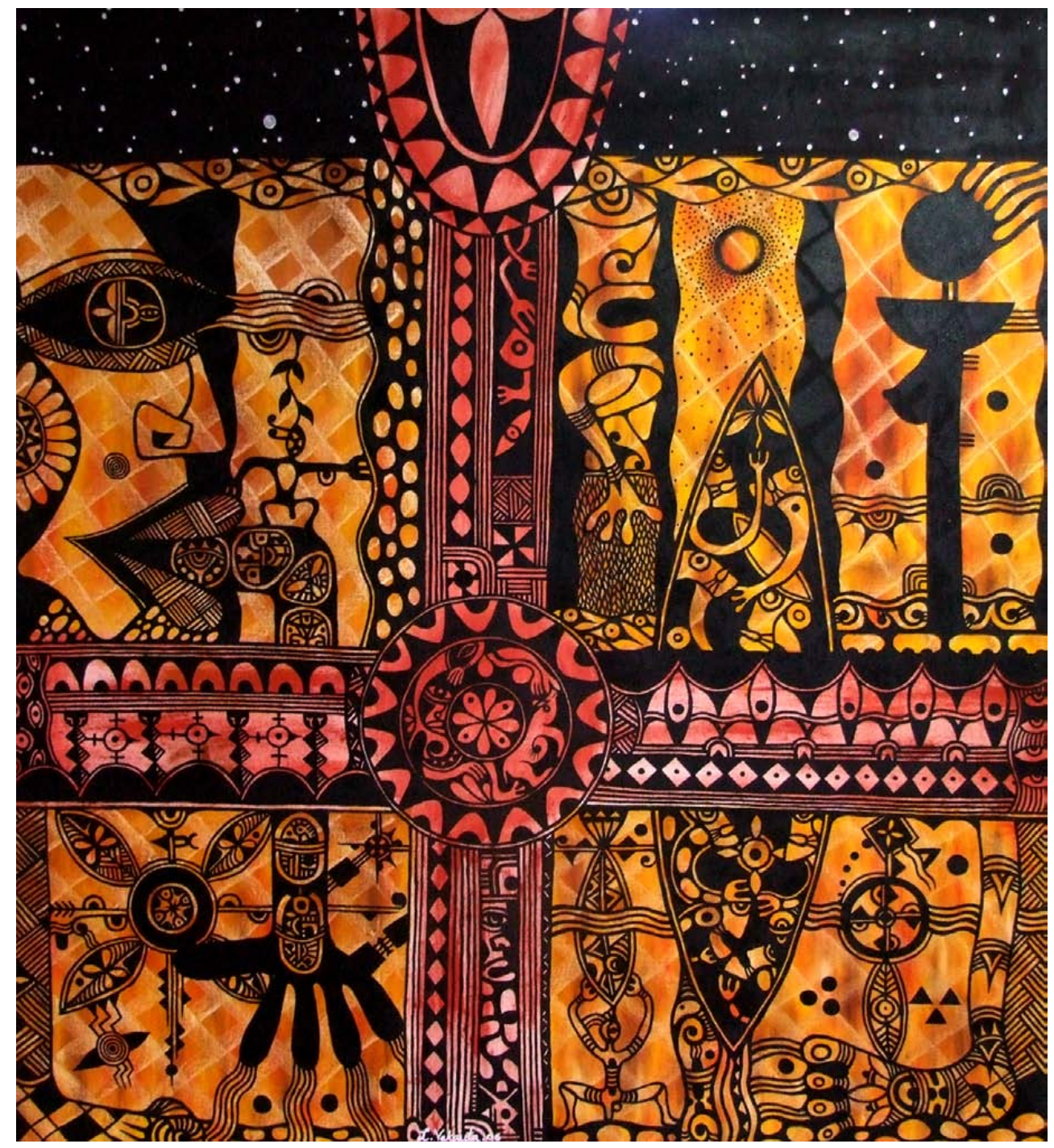

Ko e Hala (The Way)

Oil on canvas, 2006, I $84 \mathrm{~cm} \times$ I $69 \mathrm{~cm}$.

Photo by Oceania Centre staff. 


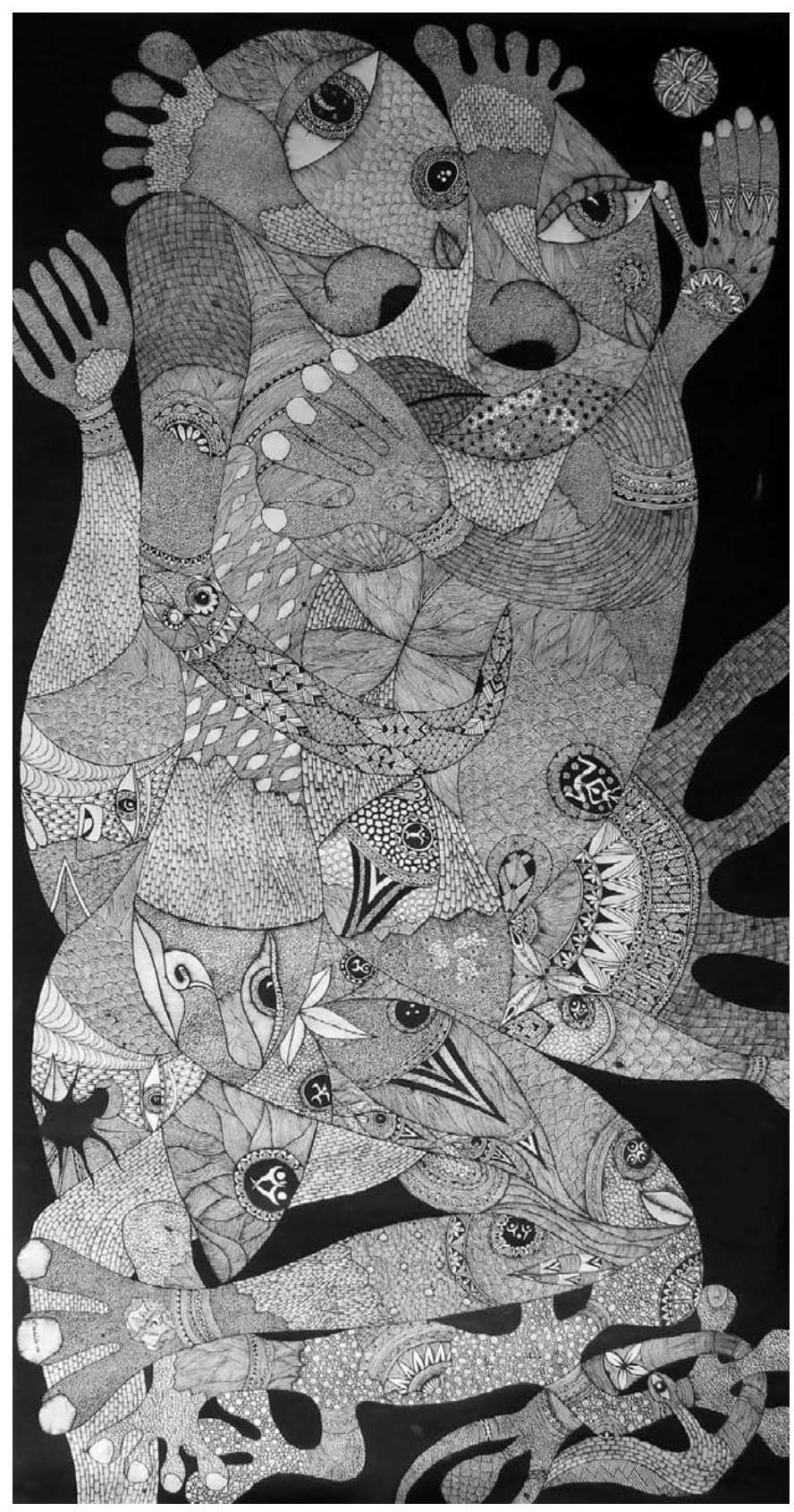

Meeting of the Fishes

Ink on paper, $2006,2 \mathrm{I} 9 \mathrm{~cm} \times \mathrm{II} 4 \mathrm{~cm}$.

Photo by Oceania Centre staff. 


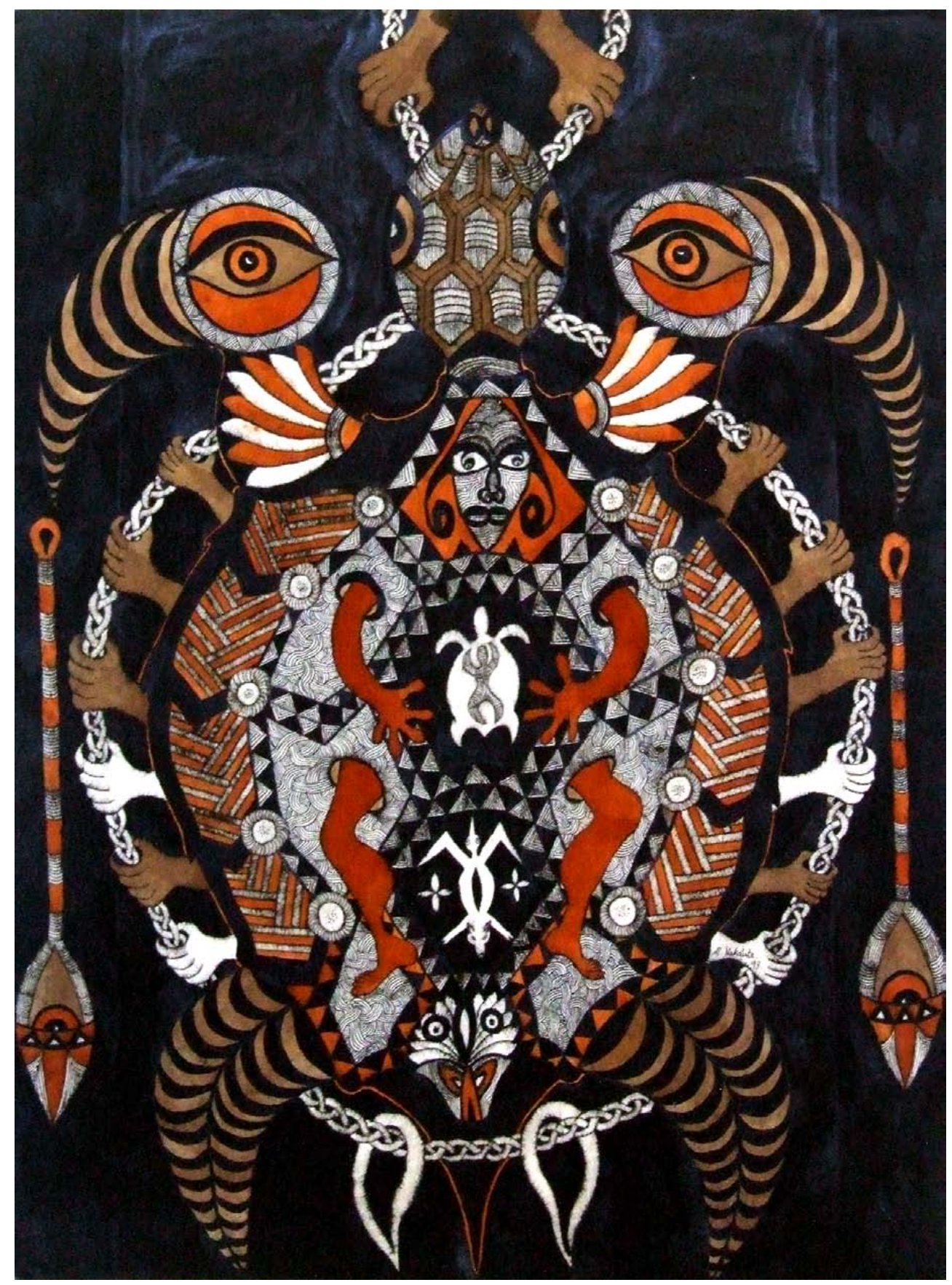

The Riddles of Sangone

Ink on paper, I998, $77 \mathrm{~cm} \times 57 \mathrm{~cm}$.

Photo by Katherine Higgins. 


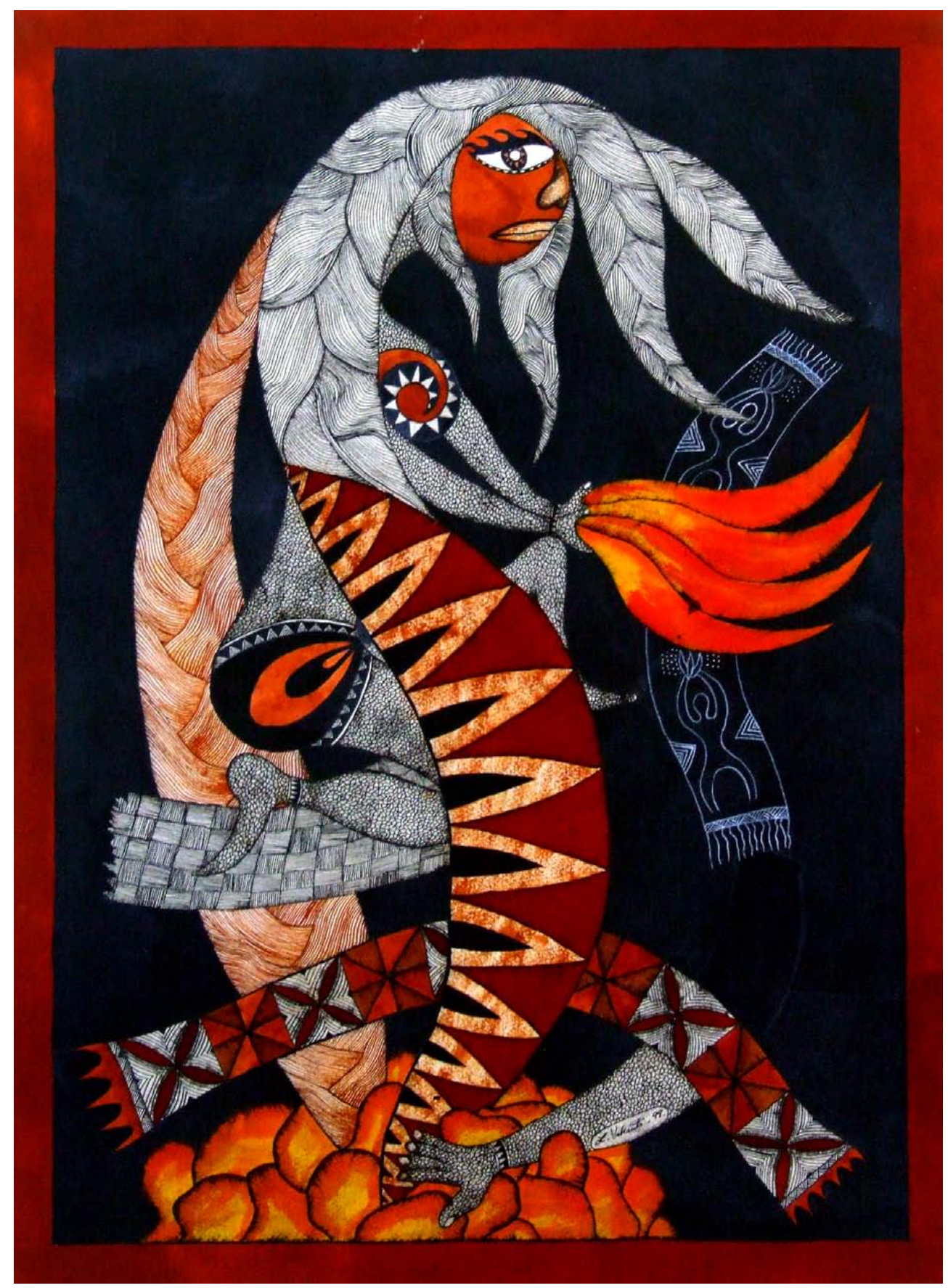

Fire Keeper

Ink on paper, I999, $77 \mathrm{~cm} \times 57 \mathrm{~cm}$.

Photo by Katherine Higgins. 


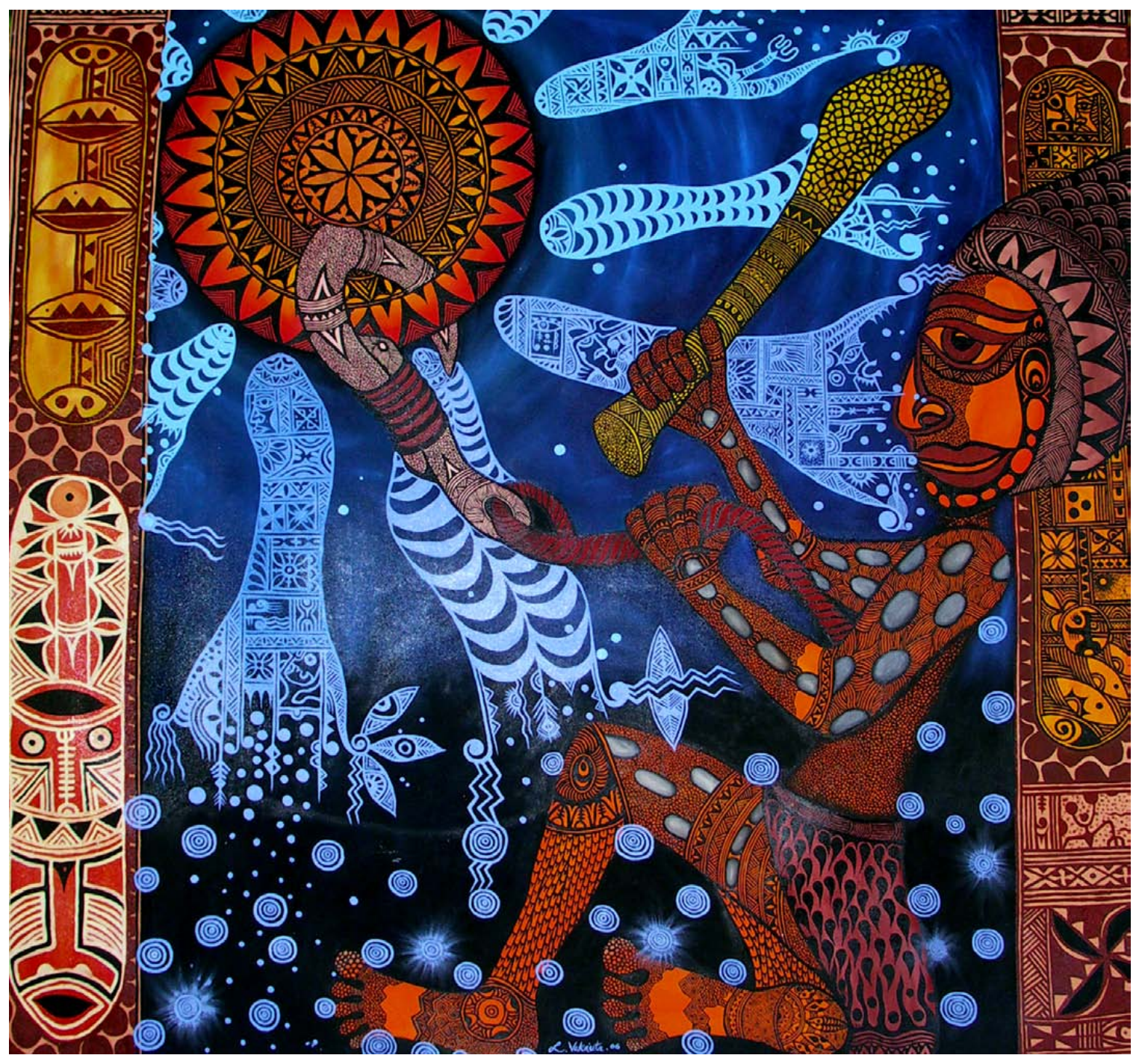

The Legend of Maui Slowing the Sun

Oil on canvas, $2006,190 \mathrm{~cm} \times 170 \mathrm{~cm}$.

Photo by Oceania Centre staff. 


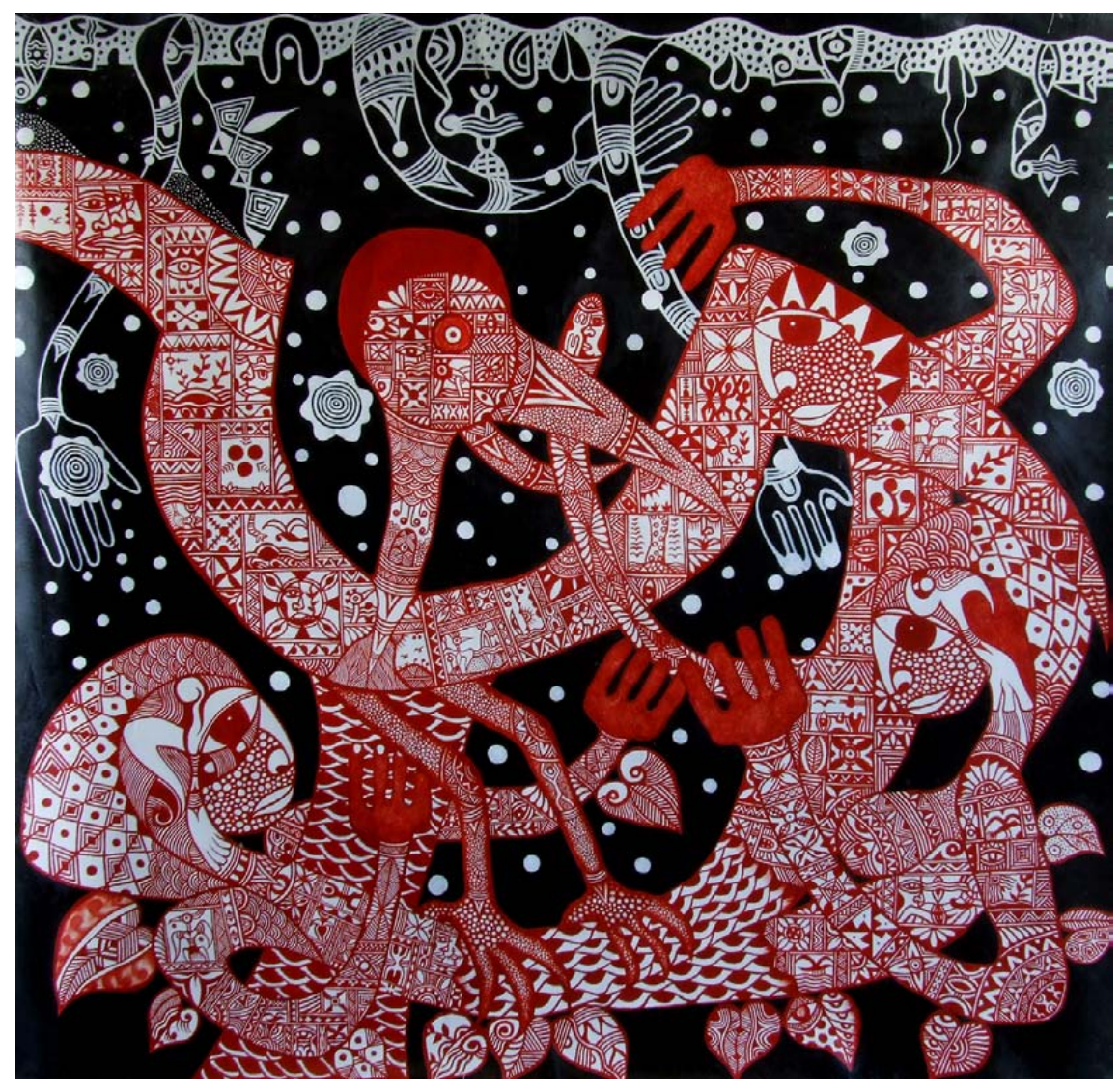

Kohai, Koau, Ko Momo (Who, Me, and Momo), The First Human Beings of Tonga Oil on canvas, $2006,190 \mathrm{~cm} \times 198 \mathrm{~cm}$. Photo by Oceania Centre staff. 